\title{
Reação de genótipos de algodoeiro à mancha de Ramularia em diferentes épocas e ambientes
}

\author{
Edivaldo Cia ${ }^{1,4}$, Milton Geraldo Fuzatto ${ }^{1}$, Júlio Isao Kondo ${ }^{1}$, Guilherme de Almeida $\mathrm{Ohl}^{2}$, Rafael Galbieri ${ }^{3}$
}

\author{
${ }^{1}$ Instituto Agronômico, Av. Barão de Itapura, 1481, 13020-902, Campinas-SP; ${ }^{2}$ Ceres Consultoria Agronômica; ${ }^{3}$ Instituto Mato-grossense do \\ Algodão; ${ }^{4}$ Bolsista do CNPq. \\ Autor para correspondência: Edivaldo Cia (cia@iac.sp.gov.br) \\ Data de chegada: 24/04/2012. Aceito para publicação em: 25/04/2013.
}

1816

\section{RESUMO}

Cia, E.; Fuzatto, M.G.; Kondo, J.I.; Ohl, G.A.; Galbieri, R. Reação de genótipos de algodoeiro à mancha de Ramularia em diferentes épocas e ambientes. Summa Phytopathologica, v.39, n.3, p.193-197, 2013.

Genótipos de algodoeiro, compreendendo cultivares e linhagens avançadas, foram avaliados quanto à reação à mancha de Ramularia (Ramularia areola), em experimentos de campo e sob infestação natural, aos 60;90 e 110 dias após a emergência das plantas em Ituverava-SP, e aos 75; 100 e 120 dias em Primavera do Leste-MT. Nos dois locais a avaliação mais tardia foi fundamental para discriminar adequadamente os genótipos e determinar seu grau efetivo de resistência ao patógeno. As avaliações realizadas mais cedo ou foram ineficazes para isso ou subestimaram a suscetibilidade de alguns genótipos. Interação genótipo $\mathbf{x}$ ambiente altamente significativa e correlação muito baixa, não significativa, entre as notas médias dos genótipos nos dois experimentos, expressaram desempenho contraditório de alguns genótipos, conforme o local, indicando possível existência de variabilidade genética desse patógeno no Brasil.

Palavras-chave adicionais: Ramularia areola, resistência genética, variabilidade do patógeno.

\section{ABSTRACT}

Cia, E.; Fuzatto, M.G.; Kondo, J.I.; Ohl, G.A.; Galbieri, R. Reaction of cotton genotypes to areolate mildew at different times and environments. Summa Phytopathologica, v.39, n.3, p.193-197, 2013.

Cotton genotypes, comprising cultivars and advanced lineages, were evaluated for their reaction to areolate mildew (Ramularia areola) in field experiments under natural infestation, at 60,90 and 110 days after plant emergence in Ituverava-SP, and at 75, 100 and 120 days in Primavera do Leste-MT. In both localities, the latest evaluation was fundamental to adequately discriminate the genotypes and determine their effective degree of resistance to the pathogen.
The earliest evaluations were inefficacious for this or underestimated the susceptibility of some genotypes. Highly significant genotype $\mathbf{x}$ environment interaction and extremely low, non-significant correlation between the mean scores of genotypes in the two experiments expressed contradictory performance of some genotypes, according to the locality, indicating possible existence of genetic variability of this pathogen in Brazil.

Additional keywords: Ramularia areola, genetic resistance, pathogen variability.

Considerada, durante muito tempo, doença secundária do algodoeiro, no Brasil, a mancha de Ramularia (Ramularia areola) constitui, atualmente, problema relevante na maioria das regiões produtoras de algodão no País. Contribuiu para isso, o incremento da cultura na região Centro-Oeste brasileira, com pluviosidade e umidade do ar elevadas, e, sobretudo, o emprego nas lavouras de cultivares altamente suscetíveis ao patógeno. Em tais condições, a despeito de cuidados para evitar plantios adensados e sombreamento excessivo entre plantas, o controle da doença vem sendo realizado predominantemente com o emprego de fungicidas em numero crescente de aplicações, não raro em torno de dez, nos casos de incidências mais severas $(1,9)$. Em tal situação, sob qualquer aspecto que se analise o problema - econômico, ambiental ou da possível resistência do patógeno aos produtos disponíveis - é evidente a necessidade de emprego, nas lavouras, de cultivares resistentes ou tolerantes a essa doença. A esse respeito, sabe-se da existência de considerável diversidade genética em cultivares e linhagens de algodoeiro disponíveis no $\operatorname{Brasil}(2,3,4,5)$, o que encoraja a identificação ou o desenvolvimento de genótipos que permitam, se não eliminar de todo, pelo menos, reduzir substancialmente o uso de fungicidas para o controle desse patógeno. Trabalhos dessa natureza exigem, obviamente, avaliações eficientes e seguras dos genótipos testados, o que implica determinar se existem épocas mais adequadas para sua realização e verificar a existência de interação genótipo $\mathbf{x}$ ambiente, que possa significar 
tanto instabilidade fenotípica da resistência dos genótipos, conforme a severidade da incidência da doença, quanto a possível existência de variantes genéticas do patógeno. Este trabalho teve por objetivo verificar o fundamento dessas hipóteses.

Dois experimentos de campo foram conduzidos, no ano agrícola 2009/10, um em Ituverava-SP e outro em Primavera do Leste-MT, para estudo de 18 genótipos de algodoeiro, compreendendo cultivares e linhagens avançadas, desenvolvidas por entidades diversas que atuam no melhoramento genético dessa planta no Brasil. Delineados em blocos ao acaso, com cinco repetições, parcelas experimentais constituídas por uma linha com $5 \mathrm{~m}$ de comprimento, e estande de 35 plantas, os ensaios foram instalados em áreas com histórico de ocorrência natural da mancha de Ramularia. Em Ituverava-SP o ensaio foi instalado em 02/12/ 2009, com adubação de $300 \mathrm{~kg} /$ ha da fórmula 4-20-20 no sulco de plantio. Foi feito desbaste e acerto de estande aos 32 dias após a emergência, ocasião em que se fez também adubação em cobertura, na base de $350 \mathrm{~kg} / \mathrm{ha}$ da fórmula 20-0-20. Em Primavera do LesteMT a semeadura foi realizada em 15/12/2009, empregando-se no sulco de plantio $350 \mathrm{~kg} / \mathrm{ha}$ da fórmula 5-22-10. O desbaste e acerto de estande foram feitos 28 dias após a emergência, aplicando-se em cobertura, na ocasião, $400 \mathrm{~kg} / \mathrm{ha}$ da fórmula 20-0-20. Os dois experimentos foram conduzidos com bom nível técnico, especialmente com respeito ao controle de plantas daninhas e de pragas, não se aplicando, porém, em nenhum deles, produtos fungicidas. Constatada a incidência da doença, foram realizadas, em cada local, três avaliações, aos 60; 90 e 110 dias de idade das plantas, em Ituverava-SP, e aos 75; 100 e 120 dias em Primavera do Leste-MT. Para tanto, foram atribuídas, a nível de parcelas, notas de 1 a 5, crescentes com a intensidade dos sintomas, conforme exposto por Cia et al. (4), a saber: nota 1 - plantas sem sintomas; nota 2 - até $30 \%$ das plantas com no máximo duas folhas apresentando poucas, pequenas e esparsas lesões típicas (manchas angulosas e com aspecto farináceo); nota 3 - de 50 a $80 \%$ das plantas com a maioria das folhas apresentando lesões equivalentes a nota 2 , ou cerca de metade das plantas com número e tamanho médio de lesões; nota 4 - mais de $80 \%$ das plantas com a maioria das folhas apresentando número e tamanho médio de lesões; e nota 5 - praticamente todas as plantas com a maioria das folhas apresentando lesões grandes, tomando quase todo o limbo foliar. Os dados, transformados em $(\mathrm{x})^{0,5}$, foram submetidos à análise de variância e ao teste de agrupamento de médias, de Scott \& Knott.

Nas Tabelas 1 e 2 encontram-se os resultados obtidos, respectivamente, em Ituverava e Primavera do Leste. De início, verifica-se que, nas duas localidades, foi altamente significativo o efeito de épocas de avaliação, cada uma delas representando efetivamente ambientes distintos, com respeito à intensidade geral de ocorrência da doença. O que importa verificar, para confirmação da primeira hipótese do trabalho, é se isso teve reflexos na eficiência da avaliação dos genótipos.

Tabela 1. Notas médias atribuídas a genótipos de algodoeiro em avaliações para a mancha de Ramularia, realizadas em três épocas em Ituverava-SP no ano agrícola 2009/10.

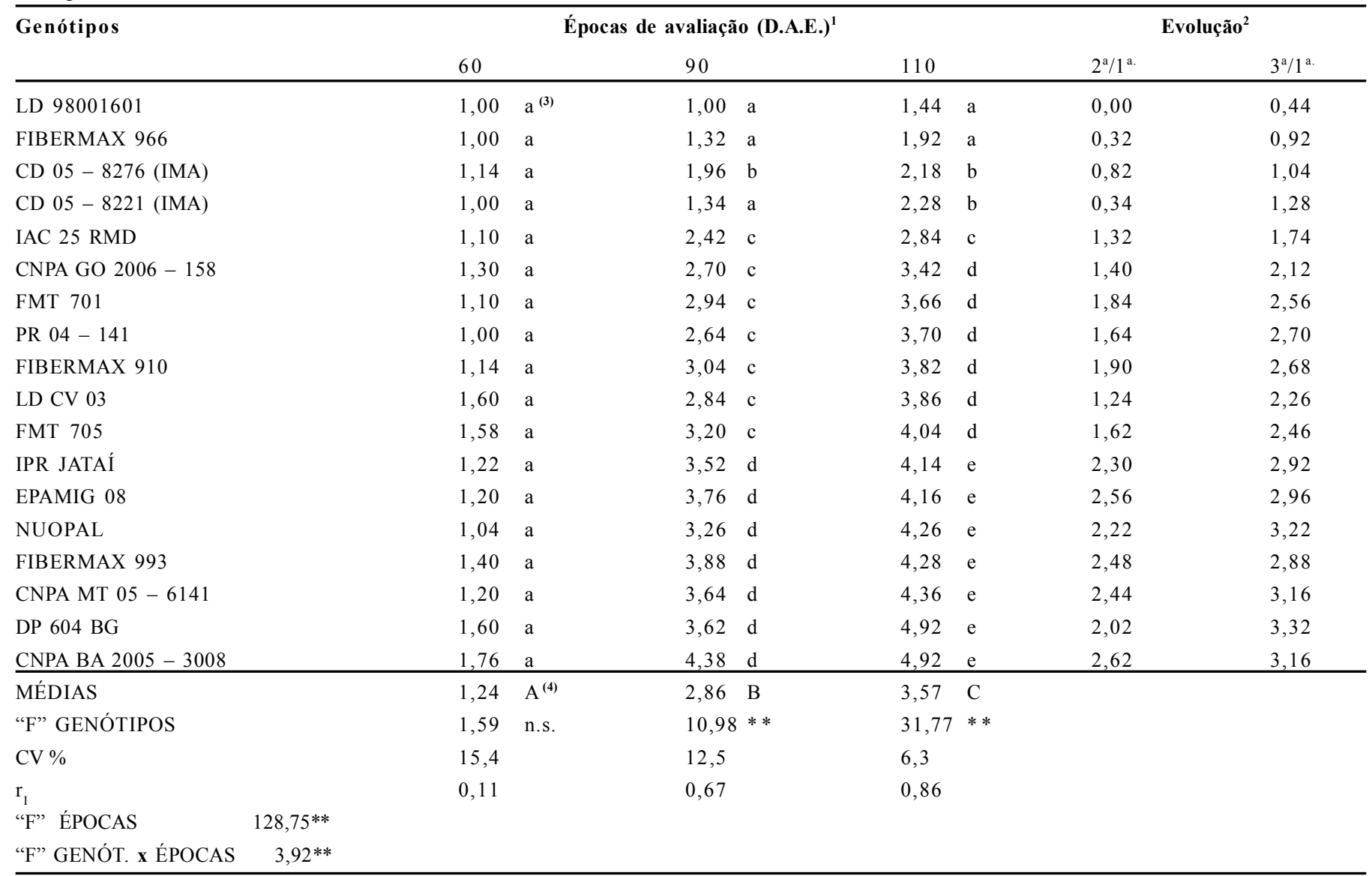

${ }^{1}$ Dias após a emergência das plantas. ${ }^{2}$ Aumento das notas na segunda e terceira avaliações em relação à primeira. ${ }^{3}$ Teste de Scott \& Knott a $5 \%$. ${ }^{4}$ Teste de Tukey a $5 \%$ para comparação de épocas. 


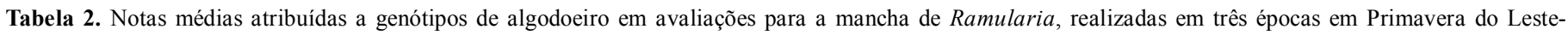
MT no ano agrícola 2009/10.

\begin{tabular}{|c|c|c|c|c|c|c|c|c|c|}
\hline \multirow{2}{*}{\multicolumn{2}{|c|}{ Genótipos }} & \multicolumn{5}{|c|}{ Épocas de avaliação (D.A.E.) ${ }^{1}$} & & \multicolumn{2}{|c|}{ Evolução ${ }^{2}$} \\
\hline & & 75 & & 100 & & 120 & & $2^{\mathrm{a} / 1^{\mathrm{a}}}$ & $3^{\mathrm{a}} / 1^{\mathrm{a}}$ \\
\hline FMT 705 & & 1,40 & $a^{(3)}$ & 1,40 & $\mathrm{a}$ & 1,48 & $\mathrm{a}$ & 0,00 & 0,08 \\
\hline CD $05-8276$ (IMA) & & 1,60 & $\mathrm{a}$ & 1,70 & $\mathrm{a}$ & 2,52 & $\mathrm{~b}$ & 0,10 & 0,92 \\
\hline CNPA GO $2006-158$ & & 1,60 & $\mathrm{a}$ & 1,50 & $\mathrm{a}$ & 2,86 & $\mathrm{~b}$ & 0,00 & 1,26 \\
\hline CD $05-8221$ (IMA) & & 1,50 & $\mathrm{a}$ & 1,70 & $\mathrm{a}$ & 3,02 & $\mathrm{~b}$ & 0,20 & 1,52 \\
\hline DP 604 BG & & 1,50 & $\mathrm{a}$ & 2,10 & $\mathrm{~b}$ & 3,26 & $\mathrm{c}$ & 0,60 & 1,76 \\
\hline IAC 25 RMD & & 1,60 & $\mathrm{a}$ & 2,00 & $\mathrm{~b}$ & 3,40 & $\mathrm{c}$ & 0,40 & 1,80 \\
\hline FMT 701 & & 1,60 & $\mathrm{a}$ & 2,20 & $\mathrm{~b}$ & 3,40 & $\mathrm{c}$ & 0,60 & 1,80 \\
\hline FIBERMAX 910 & & 1,50 & $\mathrm{a}$ & 1,90 & $\mathrm{~b}$ & 3,52 & $\mathrm{c}$ & 0,40 & 2,02 \\
\hline FIBERMAX 993 & & 1,40 & $\mathrm{a}$ & 2,00 & $\mathrm{~b}$ & 3,60 & $\mathrm{c}$ & 0,60 & 2,20 \\
\hline IPR JATAÍ & & 1,50 & $\mathrm{a}$ & 1,60 & $\mathrm{a}$ & 3,80 & $\mathrm{c}$ & 0,10 & 2,30 \\
\hline CNPA MT $05-6141$ & & 1,50 & $\mathrm{a}$ & 1,90 & $\mathrm{~b}$ & 3,82 & $\mathrm{c}$ & 0,40 & 2,32 \\
\hline NUOPAL & & 1,70 & $\mathrm{a}$ & 2,50 & $\mathrm{~b}$ & 3,98 & $\mathrm{c}$ & 0,80 & 2,28 \\
\hline LD 98001601 & & 1,50 & $\mathrm{a}$ & 1,60 & $\mathrm{a}$ & 4,04 & $\mathrm{c}$ & 0,10 & 2,54 \\
\hline PR 04-141 & & 1,60 & $\mathrm{a}$ & 2,00 & $\mathrm{~b}$ & 4,20 & $\mathrm{c}$ & 0,40 & 2,60 \\
\hline FIBERMAX 966 & & 1,50 & $\mathrm{a}$ & 1,60 & $\mathrm{a}$ & 4,22 & $\mathrm{c}$ & 0,10 & 2,72 \\
\hline CNPA BA $2005-3008$ & & 1,80 & $\mathrm{a}$ & 2,40 & $\mathrm{~b}$ & 4,24 & $\mathrm{c}$ & 0,60 & 2,44 \\
\hline LD CV 03 & & 1,80 & $\mathrm{a}$ & 2,10 & $\mathrm{~b}$ & 4,34 & $\mathrm{c}$ & 0,30 & 2,54 \\
\hline EPAMIG 08 & & 1,50 & $\mathrm{a}$ & 2,30 & $\mathrm{~b}$ & 4,40 & $\mathrm{c}$ & 0,80 & 2,90 \\
\hline MÉDIAS & & 1,56 & $\mathrm{~A}^{(4)}$ & 1,92 & $\mathrm{~B}$ & 3,56 & $\mathrm{C}$ & & \\
\hline "F” GENÓTIPOS & & 1,12 & n.s. & 2,05 & $*$ & 5,38 & $* *$ & & \\
\hline $\mathrm{CV} \%$ & & 7,5 & & 12,5 & & 11,4 & & & \\
\hline $\begin{array}{l}\mathrm{r}_{\mathrm{I}} \\
\text { "F" ÉPOCAS }\end{array}$ & $141,49 * *$ & 0,02 & & 0,17 & & 0,47 & & & \\
\hline "F" GENÓT. x ÉPOCAS & $2,51 * *$ & & & & & & & & \\
\hline
\end{tabular}

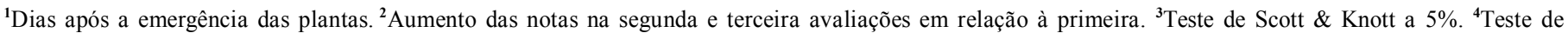
Tukey a 5\% para comparação de épocas.

Conforme se verifica na Tabela 1, referente a Ituverava, na primeira avaliação não houve diferenças estatísticas entre os genótipos. $\mathrm{Na}$ segunda foram constituídos quatro grupos de desempenho e na terceira, cinco se formaram. Quando se observa a evolução da doença e, sobretudo, as notas na última avaliação, verifica-se que foram poucos os genótipos com nível bom e estável de resistência. A segunda avaliação, embora mais eficaz do que a primeira, teria resultado na subestimação da suscetibilidade de diversos genótipos. Os dados de Primavera do Leste, Tabela 2, apresentam a mesma tendência: a primeira avaliação não discriminou os genótipos, a segunda resultou em dois e a terceira em três grupos de desempenho. Nessa localidade, a subestimação da suscetibilidade, na segunda avaliação, foi ainda mais flagrante, envolvendo a maioria dos genótipos. Vale ressaltar, por fim, a superioridade da terceira avaliação com respeito à consistência $\mathrm{e}$ repetibilidade dos dados, conforme se verifica pelos coeficientes de correlação intra-classe $\left(r_{\mathrm{I}}\right)$, inseridos nas tabelas. Em síntese, ressalvada a possibilidade de desfolha das plantas, devida à doença, o que comprometeria a avaliação, esta seria mais eficaz se realizada após 110 - 120 dias a contar da emergência, em comparação com as efetuadas em estágios anteriores.

A segunda hipótese do trabalho, envolvendo discrepâncias de desempenho de genótipos, em regiões diversas, foi confirmada pela interação genótipos x localidades ("F" $=10,61^{* *}$ ), na análise conjunta dos dados da terceira avaliação. Como se verifica nas Tabelas 1 e 2 e na Figura 1, essa interação e a baixa correlação entre as médias dos genótipos nos dois locais $(\mathrm{r}=0,09)$, expressa resultados contraditórios como os dos genótipos FMT 705, resistente em Primavera do Leste e suscetível em Ituverava e, contrariamente, FIBERMAX 966 e LD 98001601 suscetíveis na primeira e resistentes na segunda das localidades citadas. Tais resultados contrastam com reações coerentes nas duas localidades como as dos genótipos CD $05-8276$, resistente em ambas, e IAC 25 RMD e CNPA BA 2005 - 3008, medianamente resistente e suscetível, respectivamente, também nos dois locais. Os desempenhos irregulares observados poderiam ser explicados pela instabilidade fenotípica da resistência de alguns genótipos, em função da intensidade de ocorrência da doença, como já foi apontado por Fuzatto et al. $(7,8)$ para esse e outros patógenos. Isto parece não acontecer no presente caso, uma vez que, na média dos genótipos, especialmente na terceira avaliação, a intensidade da doença foi semelhante nos dois locais. Isso leva a considerar a segunda possibilidade aventada, a de que resultados como os obtidos neste trabalho constituem indicativo da ocorrência, em tais localidades, de variantes genéticas do patógeno, conforme hipótese formulada, em trabalho anterior, por Cia et al. (6), fato este de considerável importância prática, como é o caso da cultivar FMT 705, avaliada como resistente no Estado de Mato Grosso e que se mostrou suscetível em regiões dos estados de São Paulo e Goiás ( 3). Qualquer que fosse, contudo, a explicação, o que vale ressaltar é a influência do ambiente, assim como da época, em que se realiza a avaliação, para classificação segura da resistência de genótipos de algodoeiro ao patógeno considerado. 

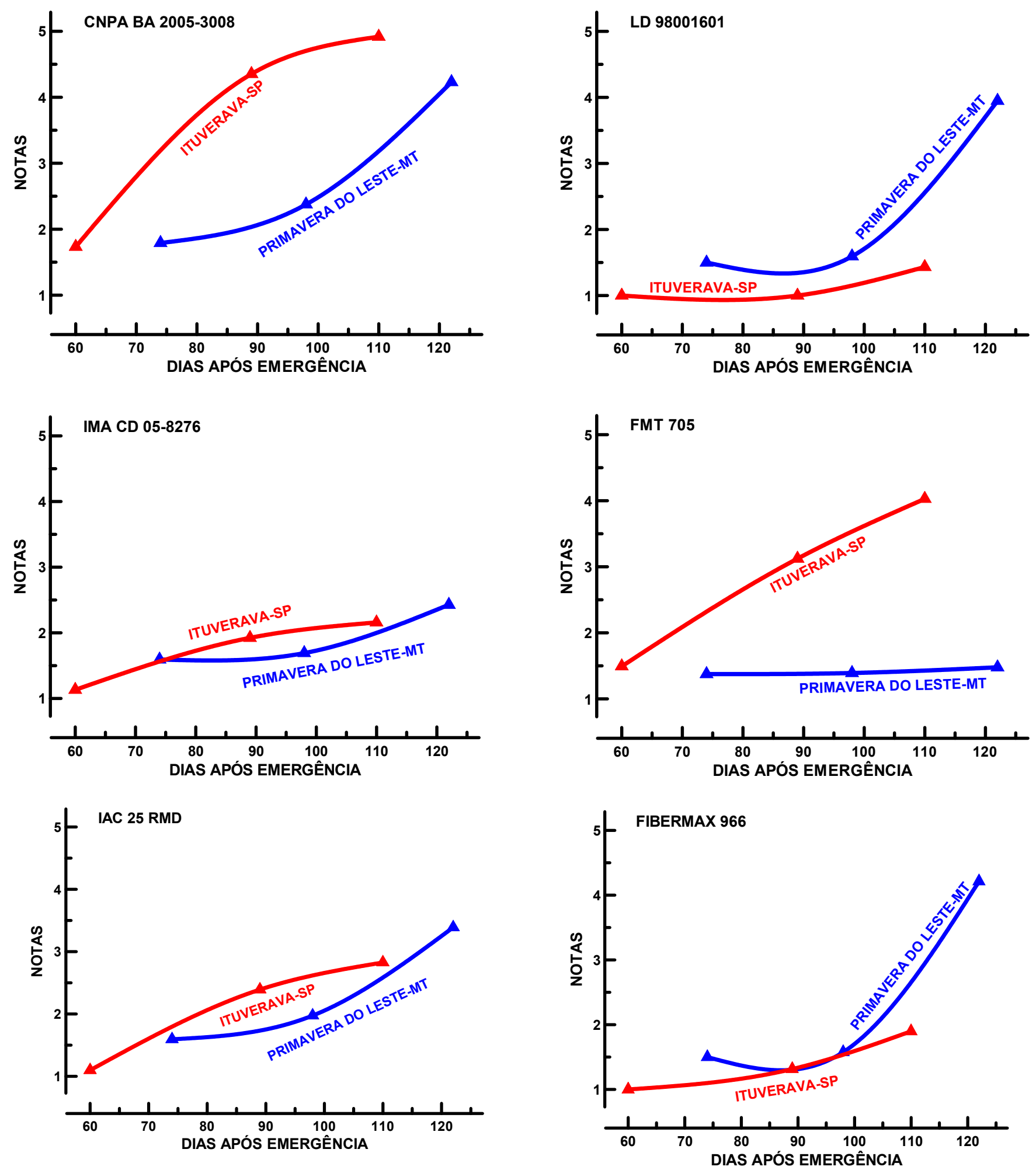

Figura 1 - Variabilidade de Ramularia areola observada em genótipos de algodoeiro no ano agrícola de 2009/10.

\section{AGRADECIMENTOS}

Trabalho realizado com apoio da FAPESP, do CNPq, do IMA e do FIALGO.

\section{REFERÊNCIAS BIBLIOGRÁFICAS}

1. Andrade Júnior, E.R.; Galbieri, R.; Vilela, P.A.; Ferrari, S.; Boldt, A.F. Controle químico da mancha de Ramularia (Ramularia areola) no algodoeiro em Campo Verde-MT. In: Congresso Brasileiro de Algodão, 7, 2009. Foz do Iguaçu. Anais... Campina Grande: EMBRAPA/Algodão, 2009. 1 CD-ROM. 
2. Cia, E.; Fuzatto, M.G.; Kondo, J.I.; Galbieri, R.; Lüders, R.R.; Almeida, W.P.; Oliveira, A.B.; Krzyzanowsky, A.A.; Lebedenco, A.; Martins, A.L.M.; Morello, C.L.; Pereira, D.J.; Mesquita Neto, D.R.; Bolonhezi, D.; Foltran, D.E.; Chiavegato, E.J.; Machado, E.F.; Furlani Junior, E.; Takizawa, E.K.; Dias, F.L.F.; Farias, F.J.C.; Kasai, F.S.; Ohl, G.A.; Cunha, E.F.; Belot, J.L.; Cavichioli, J.C.; Carvalho, L.H.; Berian, L.O.S.; Oliveira, M.A.C.; Lanza, M.A.; Ito, M.A.; Pereira, M.; Michelotto, M.D.; Ito, M.F.; Pedrosa, M.B.; Suassuna, N.D.; Vilela, P.A.; Gallo, P.B.; Reco, P.C.; Aguiar, P.H.; attos, R.E.M.F.;. Freitas, R.S.. Desempenho de cultivares e linhagens de algodoeiro em face da ocorrência de doenças e nematoides: Resultados de 2007/08 e 2008/09. Boletim Científico do Instituto Mato-Grossense do Algodão, Cuiabá, no. 2, p.1-66, 2011.

3. Cia, E.; Fuzatto, M.G.; Kondo, J.I.; Gallo, P.B. Reação de cultivares e linhagens de algodoeiro à incidência de mancha de Ramularia. In: Congresso Brasileiro de Algodão, 8., 2011, São Paulo. Anais.... Campina Grande: EMBRAPA/Algodão, p.1430-1433, 2011. 1 CD ROM

4. Cia, E.; Fuzatto, M.G.; Lüders, R.R.; Kondo, J.I; Galbieri, R.; Almeida, W.P.; Oliveira, A.B.; Lebedenco, A.; Pereira, A.T.; Martins, A.L.M.; Campos, D.J.T.; Mesquita, D.; Bolonhezi, D.; Foltran, D. E.; Chiavegato, E.J.; Moresco, E.; Furlani Jr, E.; Takizawa, E.K.; Melo, F.L.A.; Dojas, F.; Farias, F.J.C.; Kasai, F.S.; Cunha, E.F.; Belot, J.L.; Silva, J.C.; Carvalho, L.H.; Beriam, L.O.S.; Lanza, M.A.; Ito, M.A.; Pereira, M.; Michelotto, M.D.; Ito, M.F.; Pedrosa, M.B.; Ruano, O.; Pupim Junior, O.; Gallo, P.B.; Reco, P.C.; Aguiar, P.H.; Rossetto, R.; Freitas, R.S.; Muramoto, S.P. Desempenho de cultivares e linhagens de algodoeiro em face da ocorrência de doenças e nematoides. Boletim Científico do Instituto Mato-Grossense do Algodão, Cuiabá,, no. 1, p. 1-38, 2008.

5. Cia, E.; Fuzatto, M.G.; Martins, A.L.; Michelotto, M.D.; Almeida, W.P.; Oliveira, A.P. Reação de genótipos de algodoeiro à incidência da mancha de Ramularia em condições naturais de infestação. In: Congresso Brasileiro de Algodão, 7. 2009, Foz do Iguaçu. Anais... Campina Grande: EMBRAPA/Algodão, p.1452-1455, 2009. 1 CDROM.

6. Cia, E.; Galbieri, R.; Fuzatto, M.G.; Kondo, J.I.; Oliveira, A.B. Indicativo de variabilidade de Ramularia areola em algodoeiro no Brasil. In: XXXIII Congresso Paulista de Fitopatologia, Ituverava-SP, 2011. Summa Phytopathologica, Botucatu, v. 36. 1 CD ROM.

7. Fuzatto, M.G.; Cia, E.; Kondo, J.I. Estabilidade fenotípica, um complemento relevante na avaliação e classificação de genótipos de algodoeiro para resistência a doenças. In: Congresso Brasileiro de Algodão, 8., 2011. São Paulo. Anais.... Campina Grande: EMBRAPA/Algodão, p. 1382-1388, 2011. 1 CD-ROM.

8. Fuzatto, M.G.; Cia, E.; Lüders, R.R.; Galbieri, R.; Kondo, J.I. Estabilidade fenotípica com critério de avaliação de genótipos de algodoeiro para resistência à ramulose. Congresso Brasileiro de Algodão, 7., 2009, Foz do Iguaçu. Anais.... Campina Grande: EMBRAPA/Algodão, p. 1675-1679, 2009. 1 CD-ROM.

9. Suassuna, N.D.; Coutinho, W.M.; Asmus, G.L.; Inomoto, M.M.; Chitarra, L.G. Manejo de doenças do algodoeiro. In: Beltrão, N. E.de M.; Azevedo, D.M.P de. (Ed.). O Agronegócio do Algodão no Brasil Brasília: EMBRAPA/Algodão, 2011. V.2, cap. 29, p.983-1032. 